\title{
ACTIVE LABOR MARKET POLICIES AGAINST YOUTH UNEMPLOYMENT IN TIMES OF AUSTERITY: THE CASE OF GREECE
}

\author{
Aikaterini Apostolidou \\ Mrs., University of the Aegean, Greece, socd12051@soc.aegean.gr
}

\begin{abstract}
The austerity measures that Greece is invited to implement since 2009, when the country was formally announced as being in an economic crisis, resulted in a massive loss of jobs, limited government spending and created a rift in the social safety net. Youth unemployment is a complex economic and social phenomenon, the treatment of which is at the heart of economic and social policy. The unemployment rate increased for all age groups between 2008 and 2013. Youth unemployment policies are included in the new part of the general category of ALMP (Active Labor Market Policy). The key features of active labor market policies is that they constitute a supplement to the basic employment policy, as they are only small-scale interventions and targeted at specific groups of workers. The main purpose of this paper is to study the impact of active labor market policies against efforts to tackle youth unemployment, depending on the phase of the transition experience, such as whether young workers live alone or with their parents, whether they are married and have children, etc.
\end{abstract}

Keywords: Unemployment, Youth, Economic Crisis, Active Labor Market Policies

\section{INTRODUCTION}

The austerity measures that Greece is invited to do since 2009, the year in which the country is experiencing an economic crisis, resulted in a massive loss of jobs, limit government spending and create rift in the social safety net. Youth unemployment is a complex economic and social phenomenon, the treatment of which is at the heart of economic and social policy. The unemployment rate increased for all age groups between 2008 and 2013. In the third quarter of 2014 the number of the employed workforce amounted to 3.586 .885 persons, while the number of unemployed amounted to 1.229 .370 . The unemployment rate was $25.5 \%$ compared to $26.6 \%$ in the previous quarter, and $27.2 \%$ in the corresponding quarter of 2013 . The number of employed persons increased by $14 \%$ compared to the previous quarter, and by $1.5 \%$ compared to the third quarter of 2013. The number of unemployed decreased by $4.0 \%$ compared to the previous quarter and by $6.9 \%$ compared to the 3rd quarter of 2013 (EL STAT). Youth unemployment policies are included in the new part of the general category of ALMP. The key features of active labor market policies is that they constitute a supplement to the basic employment policy, as they are only small-scale interventions and targeted at specific groups of workers.

Given the above backdrop, the main research question is as follows:

What is the impact of targeted programs for youth in the efforts to tackle (youth) unemployment depending on the phase of transition in which they are (for example, whether they live alone or with their parents, whether they are married and have children, etc.)? 
The analysis is based on data of a nationwide field survey (In4Youth) which was conducted in the year 2013/2014, in several areas in Greece by the Laboratory of Social and Cultural Digital Documentation of the Department of Sociology of the University of the Aegean, whose Director and Scientific Director of this project is Prof. Sotiris Chtouris. Data collection was implemented through structured questionnaires and personal interviews and focus groups at households where young people live. The sample size was 2.000 individuals. This sample corresponds to $8 \%$ of the population $(n=2.000)$ and considered sufficient to draw some representative conclusions nationally. All 35 focus groups were conducted in order to obtain detailed information on the matter under inquiry, and the results collected as data from these groups were analyzed on a case basis during the initial stage and at a second stage, once the quantitative survey data was obtained.

Our research concluded the following key findings:

The European and government interventions on youth employment policies fail to effectively address the problem of youth unemployment.

The aim of employment programs emerges to be the creation of an affordable and fully flexible workforce, which can be adapted at any time to the demands of employers and replaces the 'expensive' age workers.

The phenomenon of 'brain drain', migration of young scientists working abroad, is a real violent removal of the workforce of the most productive portions.

\section{EMPLOYMENT POLICY AND YOUTH UNEMPLOYMENT}

\subsection{Youth Unemployment}

Unemployment is a complex social and economic phenomenon, the treatment of which is at the heart of economic and social policy. With the promotion of employment as a particular objective of governmental policy was developed a discussion on employment policies and their social and economic role. Since 1950, the achievement of full employment thanks to active demand policies and the implementation of fiscal policy measures, resulted in the development of public employment services in order to combat unemployment, mainly through the organization of occupational and geographical mobility of workers (Alber 1995). In the 1980 s the full employment policy, inspired by a Keynesian model, was gradually abandoned. The role of employment policies was referred to the support of changes in the economic cycle and their deterrent role against the downward phase and at the same time as a brake on inflation in the upward phase, arguing, in general, structural changes in the economy (Karamesini 2005).

\subsubsection{Findings of the quantitative and qualitative research In4Youth}

\subsubsection{The Employment - Unemployment - non Youth Employment Statements}

The number of unemployed young people, including those who are not seeking employment between 15-34 years of age constitutes the $2 / 3$ of the total population of the youth of the sample. Young workers represent $40 \%$ of the total population of young people between 20-34 years, which is linked to a small size of the workforce of younger ages. In 2012 Greece recorded the lowest employment rate, i.e. $33.0 \%$ of the whole of the youth population, while the average in Europe stands at $33.0 \%$, and in countries, such as Denmark, with sophisticated support for young labor market systems, the percentage in employment reaches 55.0\% (Figure 1 and Figure 2). Respectively, lower is the employment rate of the total population in Greece, i.e. $25.64 \%$, which in the same period reaches to $58.0 \%$, while the average EU gets close to $75.0 \%$ and in Denmark in 78.0\% (Eurostat, 2012).

Figure 1. Employment situation of young people aged 16-34.

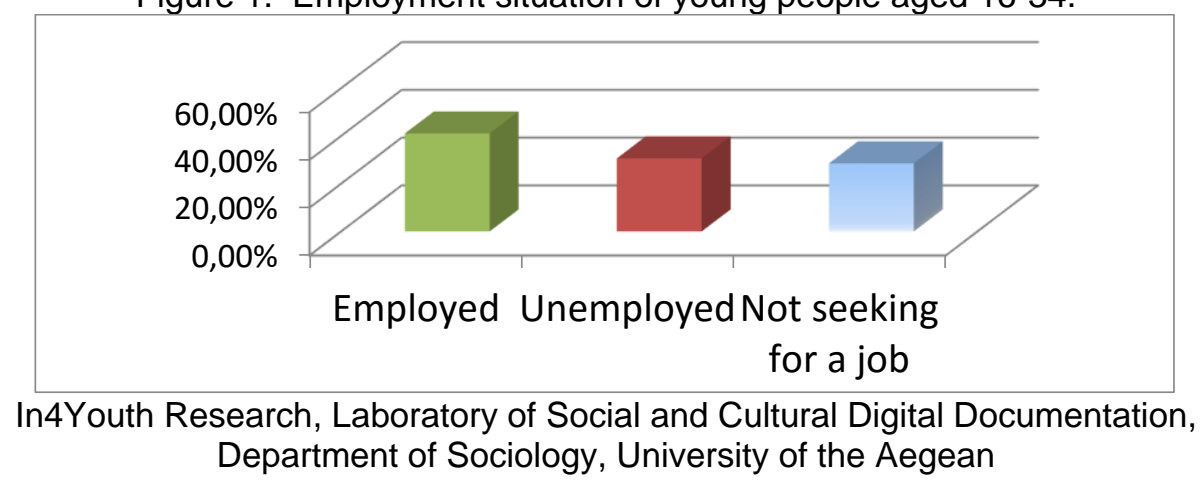




\subsubsection{Youth Unemployment in the EU countries}

Figure 2. Youth unemployment rates for the EU Member States, February 2012, August 2012 and

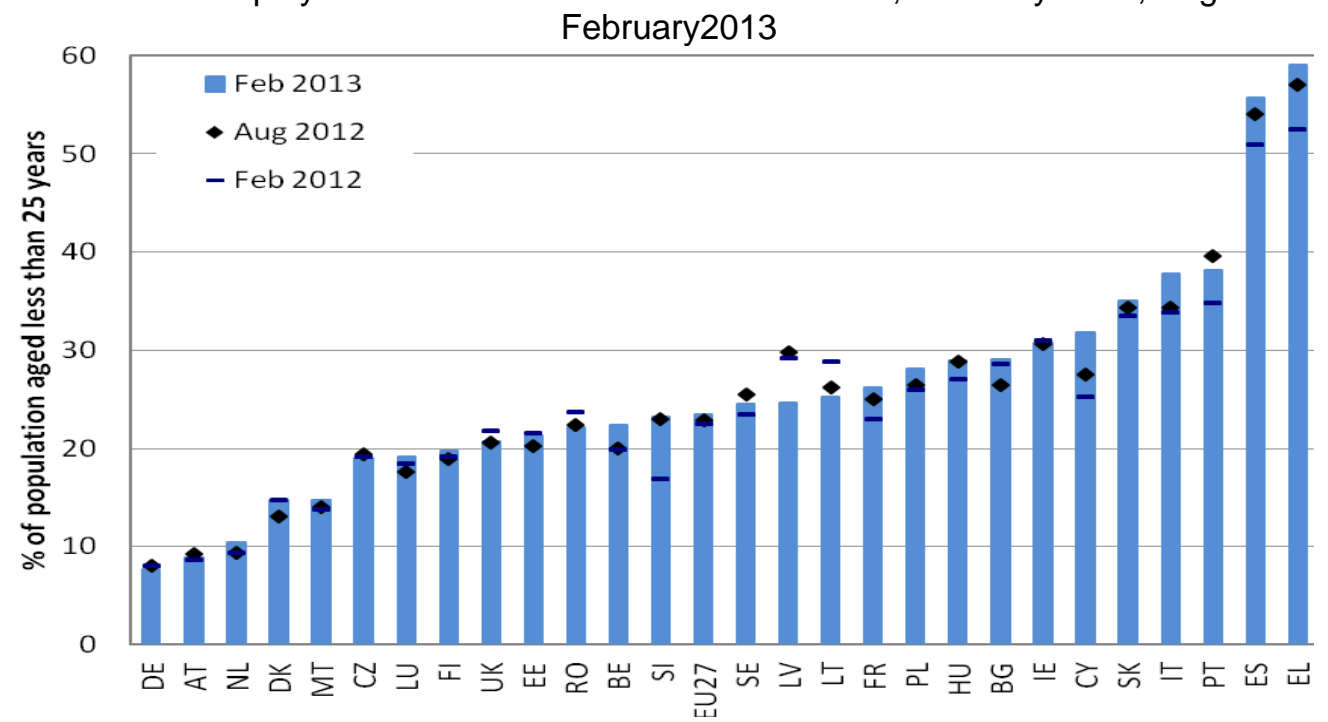

Notes: *Data for January 2013 instead of February 2013: EE, EL, HU, UK. ** Data for December 2012 instead of February 2013: CY, LV, RO, SI.

Source: Eurostat, LFS

In Greece, in 2013, the youth unemployment rate exceeded $59.1 \%$, creating a record low throughout the European Union, thus surpassing the figures of unemployment among young people aged 15-24, which Spain had until then. Southern European countries, among which Ireland, all exceeded in 2012 the threshold of $30.0 \%$, underlining the timeless low supply of jobs for young people and labor market problems in these countries. Instead, only the Netherlands, Austria and Germany showed youth unemployment rates below $10.0 \%$. The Greek situation and particularly the timeless high incidence of youth unemployment suggests that this problem is a structural problem of the economy, even before the economic crisis and is mainly determined by the following factors: a) the mismatch of supply and demand of jobs with regard to the level of education and the quality of jobs; $b$ ) the low level of remuneration and social protection leading to a long search for the desired job; and, c) the small size of firms and their inability to remain competitive after the 2009 crisis, which multiplied the intensity of an existing structural problem, adding to a greater reduction in labor supply, owing to the bankruptcy of thousands of small businesses and the indefinite suspension of already agreed appointments in the public sector (Chtouris, 2015).

Table 1. Youth unemployment rates (aged 15-24) in the European Union and in Greece from 2001 to 2013

\begin{tabular}{|l|l|l|l|l|l|l|l|l|l|l|l|l|}
\hline EU-2001 & 2002 & 2003 & 2004 & 2005 & 2006 & 2007 & 2008 & 2009 & 2010 & 2001 & 2012 & 2013 \\
\hline 17,3 & 17,9 & 18,1 & 18,6 & 18,6 & 17,3 & 15,5 & 15,6 & 19,9 & 20,9 & 21,3 & 22,8 & \\
\hline $\begin{array}{l}\text { GR- } \\
2001\end{array}$ & 2002 & 2003 & 2004 & 2005 & 2006 & 2007 & 2008 & 2009 & 2010 & 2011 & 2012 & 2013 \\
\hline 28,0 & 26,1 & 25,7 & 26,5 & 26,0 & 25,2 & 22,9 & 22,1 & 25,8 & 32,9 & 44,4 & 55,3 & 64,9 \\
\hline
\end{tabular}

Eurostat Labor Force Statistics, annual data (Ifsa_etpga) and (Ifsa_eppga). Youth aged 15-24, adults

In Table 1 it becomes evident that the high youth unemployment rates between the years 2000-2014 are accompanied by a significant reduction of employees, especially those aged $16-29$ years at $50.0 \%$, and those aged $16-35$ at $35.0 \%$. This is directly related to the acute demographic problem afflicting Greece and the reduction of youth population. This is made manifest from the reduction of the total youth population by 3,075 million people to 2,572 million people. The reduction of the total number of employees is an extremely important parameter for the education and employment policies of human resources planning (Chtouris, 2015).

\subsection{Employment Policy}

The content of employment policies is discussed often as contradictory in relevant literature, depending on the definition, which may draw on labor market policies to the flexibility policies and macroeconomic policy. In the 
early 20th century employment policies initially took the form of employment agencies, insurance against unemployment and temporary work in the public sector. However, after the Second World War employment policies spread to the economically developed countries, while the basis of commitments to full employment was undertaken by their governments ${ }^{1}$. The objectives of employment policies typically configured to specific economic and social conditions, depending on the particular problems they have to face in a society at a given time.

Employment policies include passive and active employment policies. Passive policies include the various forms of income support for the unemployed, such as unemployment benefits, social benefits and aids, aimed at limiting the consequences of unemployment in living standards for the unemployed, but also making redundancies more bearable, when these are unavoidable. The labor supply reduction policies also have a passive nature, as they absorb unemployment, without, however, increasing the volume of employment. Such policies are early retirement, staff suspension, parental and sabbatical leave from work, job sharing, etc.

Active policies are defined by the labor supply growth that increases directly employment or through reducing labor costs. Some of these policies concern the creation of jobs in the public sector, lowering non-wage labor costs and subsidization of employment in the private and social sector. The increasing occupational and geographical labor mobility and the quality improvement policies of labor supply achieved through training programs or relocation incentives, included in this kind of employment policies. The positive effect on the level of employment by increasing productivity and reducing structural unemployment, remains a key objective of these policies.

Besides financial support for the unemployed through the relevant allowances, a so-called "passive" policy, an important goal is the increasing of the employment and the refoulement of the unemployed into the labor market. In this case, the policies are directly funded by the governmental budget, the activation of the right depends on the occurrence of the unemployment risk, while the amount of the grant becomes independent of previous earnings or of the previously paid contributions and determined by the need to ensure a minimum subsistence figure (Gravaris 2003). The so-called "active labor market policies" are targeted in this point. There are several definitions formulated by researchers that highlight and reflect the particular characteristics of active labor market policies. L. Calmfors (1994) gives a general definition, considering that "Active Labor Market Policies are the measures taken to improve the labor market functioning and which are addressed to the unemployed".

According to a commonly accepted definition

Active Labor Market Policies are labor market interventions aimed at specific groups in the labor market. In this sense, they differ from the general employment policies, which, by definition, are not targeted at any particular group ... Active Labor Market Policies basically aimed at increasing the employment probability or improve income prospects for unemployed people or groups facing difficulties to enter the labor market ${ }^{2}$.

Active labor market policies refer mainly to the increase of chances of employment or the improvement of income prospects for unemployed individuals or groups who have difficulties entering the labor market; while the employment policies are generally aimed at providing income support to the unemployed or premature leavers without seeking in advance immediate improvement in labor market performance (Employment in Europe 2006).

\section{Evaluation of active labor market policies (ALMPs) and employment programs}

Given their controversial effectiveness, training programs and job creation programs arguably not only fail to reduce unemployment, but actually appear to hide the problem of unemployment under the guise of short-term solutions, as most of the participants return again in unemployment at the end of the program. By participating in these programs, there is an automatic reduction in the number of registered unemployed, but not in the actual number thereof. This occurs because the participants, although still looking for a job, are not recorded as unemployed. The difficulty to deduce accurately whether the ALMPs actually reduce the unemployment rate is thus obvious. Active labor market policies, despite the fact that they provide employment to the unemployed, essentially reduce the unemployment rate only for the limited time of their employment, since the participants are very likely to return to unemployment thereafter. As a result, it is questionable whether ALMPs

\footnotetext{
${ }^{1}$ Karamesini M., "Employment policy: coupling field of economic and social policy", Athens (Gutenberg) 2005.
}

${ }^{2}$ Employment in Europe, 2006, p. 120, European Commission, DG Social Affairs and Equal Opportunities, Unit D.1. 
have the potential to practically and substantially bring about positive change to employment rates. The reduction of unemployment depends on many factors and, therefore, the ALMPs should be embedded in broader policies tackling the problem, rather than treated as an isolated, one-off short-term intervention.

Regarding the evaluation of employment programs, despite the implementation of a youth guarantee program in Greece, it is not a reality yet. The youth guarantee program, has been firstly implemented in Finland, which developed an integrated system for this program. An evaluation of Eurofound shows that in $2011,83.5 \%$ of young jobseekers received a successful bid within three months of registering as unemployed. The Finnish system has led to personalized programs for young people who are trained faster, and this, ultimately, helps significantly to reduce unemployment (Eurofound, 2012).

But what are the factors affecting the youth guarantee program implementation: According to OECD (2014), these factors are the global economic environment, the context of national policy, local labor market conditions and the procedures of the local labor market. These agents do not operate each independently, but rather interact in various ways.

\section{Youth guarantee program implementation in other countries}

Whereas the Scandinavian countries were the first to implement the youth guarantee program as an innovative program, all countries are case studies, who have chosen different instruments to implement the program. Norway and Denmark have chosen to focus on the educational path and do not have a specific program called "guarantee". The guarantee is considered as a goal to be achieved and the Norwegians and Danes seek to combine the measures, for example by integrating the professional experience and training. In Norway, unemployment is relatively low (especially for young people on the level ISCED 5/6) and young job seekers with education and skills face fewer difficulties in finding a job. Germany, like Austria and Denmark, has a "professional job market". there is a powerful business system that absorbs over $30.0 \%$ of young people aged over 18 years. There is a greater emphasis, therefore, on learning. Classes of specific apprenticeships are also available to support young people who experience more difficulty entering the employment and training system. Poland has focused, partly only, on stimulate demand, where youth unemployment is high, even among graduates (OECD, 2014).

\section{CONCLUSIONS}

The effect of active labor market policies on the increase of employment and combating unemployment depends on many variables, some of which can only be affected by these policies. Based on this, the task of monitoring and evaluating the achievement or not of the quantified objectives relating to the employment of the workforce is extremely difficult.

In the focus of active labor market policies remains the concept of "employability": the worker as an individual subject, and by his own exclusive responsibility, is required to be for the entire period of working life "capable of" developing knowledge and skills (through retraining programs, internship, etc.), while he/she should be fully "flexible" at time, space and salary to find rudimentary "employment", according to the needs of a completely "free" and without legislative or other labor market restrictions.

What appears to be the goal of this program is the creation of inexpensive, highly flexible and at any time adaptive to the needs of the workforce enterprises, which can be recycled and "exchanged" with the more "expensive" ageing workers, ensuring at the name of competitiveness the profitability of businesses (Georgiadou 2014).

Taking into account the conditions imposed through national budgetary adjustment programs, which directly affect youth employment, applied policies have resulted in the following:

- Some features that accompany these programs, such as lack of insurance and other labor rights, the masking work employment through disguised internships etc., result in a repeat of past programs such as STAGE, which refer to cheap uninsured labor and are criticized by society, the workers, the unions, etc.

- The creation and legalization of discrimination against youth work, creating a special category of employees, those of young people at salaries reduced by at least $30.0 \%$.

- The phenomenon of 'brain drain', migration of young scientists working abroad, is a real violent removal of the workforce of the most productive portions, which is compounded by the fact that there is no net minimum social protection, which guarantees a tolerable subsistence level, which will be determined by basic needs.

It is noteworthy that the effectiveness of the proposed measures, is thinning, because of issues related to the planning and implementation of policies. Vulnerabilities, such as the lack of consistency of policies and 
measures, the fragmentation of actions, the incomplete and inadequate ways and information mechanisms, the lack of transparency and increased bureaucracy, create in practice serious obstacles and unequal opportunities for participation and often discrimination against unemployed young people who may be more affected or in need.

We conclude that the European and government interventions and youth employment policies fail to effectively address the problem of youth unemployment, but have a limited and temporary nature and constitutes management, primarily in terms that subvert the existing labor relations and rights. Based on the current situation, with regard to the world of work, a key priority is $\mathrm{d}$ the protection of full rights labor and an active and critical outlook on labor legislation.

\section{REFERENCES LIST}

Alber, J. (1995). The Development of Welfare States in Europe and America, Transaction Publishers. New Brunswick. London: Transaction Publishers.

Calmfors, L. (1994). "Active Labour Market Policy and Unemployment- A Framework for the Analysis of Crucial Design Features". OECD Economic Studies No. 22.

Chtouris, S. (2015). International Conference proceedings, Department of Sociology, University of the Aegean, on subject "Procedures for Social Integration and Labor Market integration of young people in times of economic crisis" under the act "ARISTEIA".

Employment in Europe. (2006). European Commission, DG Social Affairs and Equal Opportunities. Unit D.1.

Eurofound. (2012). Youth Guarantee: Experiences from Finland and Sweden. EF/12/42/EN.

Eurostat Statistics Explained, (2012). "Youth Unemployment".

Georgiadou, P. (2014). "Youth and Employment Policies". Journal Information. vol.217.

Gravaris D., 2003. "The Relationship of Passive and Active Policies, Employment within the Overall State Intervention in the Labor Market - Theoretical Framework and Empirical Examples". In D. Venieris and Ch. Papatheodorou (ed.) The Social Policy in Greece - Challenges and prospects. Athens. Editions Greek Letters.

Karamesini, M. (2005). "The Employment Policy as Field Coupling of Economic and Social Policy". In M. Karamesini and I. Kouzis (ed.). Employment Policies. Athens: Gutenberg.

OECD. (2014). Local Implementation of Youth Quarantees: Emerging Lessons from European Experiences. 